Article

\title{
Factors Affecting Knowledge Sharing in Virtual Teams
}

\author{
Vida Davidavičienè *(D), Khaled Al Majzoub and Ieva Meidute-Kavaliauskiene $\mathbb{D}$
}

Department of Business Technologies and Entrepreneurship, Business Management Faculty, Vilnius Gediminas Technical University, Saulètekio al. 11, 10223 Vilnius, Lithuania; khaledmajzoub@hotmail.com (K.A.M.); ieva.meidute-kavaliauskiene@vgtu.lt (I.M.-K.)

* Correspondence: vida.davidaviciene@vgtu.lt

Received: 18 June 2020; Accepted: 14 August 2020; Published: 25 August 2020

check for updates

\begin{abstract}
The development and use of information and communications technology (ICT) are growing at a rapid speed across the world. ICT has been the cause for new types of work arrangements, such as virtual organizations, virtual teams, teleworking, etc. Virtual teams provide organizations with competitive advantage by enabling them to hire talented people across the world and eliminating the need for physical availability in the office. However, one major issue hindering the productivity of the virtual team is knowledge sharing. The lack of proper knowledge sharing between team members may cause organizations to fail with regards to the implementation of successful strategies. The research into understanding knowledge sharing in virtual teams (VT) in the Middle East is lacking. While such studies have been done in the United States and Europe, the Middle East has been overlooked. In this study, the authors assume that there are some specific behavioral aspects of VT in the Middle East that create the need for specific scientific solutions. Accordingly, this study was conducted in the Middle East in order to gain scientific knowledge on the region's specificity. The objective of this article is to create a model for the evaluation of the effect on knowledge sharing in virtual teams in the Middle East. For analysis, the selection of companies includes United Arab Emirates (UAE)-based companies in the IT industry whose businesses engage in VT. The results show that the following factors have a direct effect on knowledge sharing in VT: Culture, motivation, conflict, ICT, trust, and leadership. Conversely, the results do not demonstrate that language has any impact on knowledge sharing. The methodology used is as follows: Literature review, survey methods, and structural equation modeling.
\end{abstract}

Keywords: information and communications technologies; ICT; virtual organization; virtual teams; knowledge sharing; performance

\section{Introduction}

Change in organizations occurs for several reasons; e.g., recession, budget reductions, market pressure, or advances in information and communications technology (ICT) [1]. ICT is changing every aspect of our lives, whether it is personal life, social interactions, business atmosphere, or corporate culture [2]. ICT has caused change in organizational behavior, including organizational design. Many organizations responded to these changes by introducing virtual teams (VT) whose members are geographically dispersed, and their work is organized and communicated through ICT tools [3]. Although ICT improves efficiency, it can also bring many challenges, such as cultural barriers, scheduling conflicts, response delays, lack of communication, feedback delays, misinterpretation, and time difficulties [4]. In management theory, teams are considered to be very important components in achieving organizational goals and objectives. Virtual teams are important for organizations because they allow the team members to communicate despite the constraints of time and distance. They allow 
organizations to hire the most talented people to join the team regardless of their location, which in turn increases the efficiency of the team [5]. The four key characteristics of virtual teams are as follows: They are temporary (organized for a particular task), culturally diverse (different nationalities and languages), geographically dispersed (working from remote locations), and electronically connected (using ICT for communication) [6]. Virtual teams are culturally different. Team configurations are different for each team depending on the ways the location is split and diversified [7]. Organizations using VTs face a lot of complexities. In addition to technical challenges, there are also social and psychological factors to be considered [8]. Virtual teams focus on knowledge-intensive tasks that involve the sharing and exchange of information and knowledge [9]. Currently, the competitiveness of a company is mostly derived from its intangible assets rather than its tangible ones; e.g., knowledge and the process of knowledge transfer [10]. Virtual teams remain the primary source of intangible asset acquisition in organizations [11]. Knowledge sharing is a salient aspect of virtual teams, and it is important to study and measure it within the virtual teams.

The aim of this article is to measure the effect on knowledge sharing in virtual teams in terms of the following factors: Culture, motivation, language, conflict, ICT, trust, and leadership. Accordingly, the following research question has been formulated: Are culture, motivation, language, conflict, ICT, trust, and leadership positively or negatively correlated with knowledge sharing processes? Consequently, due to their influence on knowledge sharing in virtual teams, the seven factors, i.e., culture, motivation, language, conflict, ICT, trust, and leadership, are used in the model that measures knowledge sharing in the virtual team. The methodology used is as follows: Literature review, survey methods, and structural equation modeling.

In the next section, we review the literature on knowledge sharing and the seven factors that affect it as well as present our model. This is followed by the methodology section and our conclusion.

\section{Previous Studies and Hypothesis Development}

\subsection{Literature Review}

The rising interest for businesses to access talent on demand has prompted organizations to outsource employees that would benefit them with their complementary skills, flexible schedule, and location. Such dispersion has caused organizations to face challenges in managing teams consisting of different cultures and based in different locations [12]. Virtual teams experience greater diversity than the physical ones [13]. The number of VTs has significantly increased due to the requirements for a high level of innovation, business globalization, and advances in ICT [14].

There are several definitions for virtual teams, and some are as follows:

- "As a group of people who work interdependently with a shared purpose, across space, time, and organizational boundaries, using ICT to communicate and collaborate" [15] (p. 699).

- "A team geographically dispersed and working interdependently using technology to communicate and collaborate across time and space" [16] (p. 305).

- "As groups of geographically and/or organizationally dispersed co-workers that are assembled using a combination of telecommunications and information technologies to accomplish an organizational task. A VT is a group of geographically and/or temporally dispersed individuals brought together via information and telecommunication technologies" [17] (p. 650).

- "Are relatively small, task-oriented groups of individuals who are, at least to some extent, distributed and mostly work in technology-mediated ways toward a common goal" [18] (p. 12).

Virtual teams are beneficial for both employees and employers. For employees, the benefits lie in the flexibility of working from home or a hotel room, which facilitates the work-life balance and enhances employee satisfaction. Employers benefit from the availability of experts abroad due to the advances in ICT [19]. The intellectual capacity of a diverse virtual team is in its ability to integrate expertise and to create shared knowledge [20]. The greatest problem for global virtual teams is 
developing cohesion within the team. Team diversity can both pose a difficulty and create opportunities. Many of the empirical studies done on the effect of team diversity on team performance found that it can create added value and deliver higher performance in comparison to homogeneous teams. The reason given is that diversity brings a bordered area of knowledge. Conversely, other studies found that homogeneous teams outperformed diverse teams due to the absence of team conflict and miscommunication. Virtual teams need to be managed correctly to become high-performance teams. Two types of diversity exist, i.e., surface-level diversity and deep-level diversity [20]. Lately, there has been an increase of interest in studying the process that makes teams successful. The question has shifted from what makes teams successful to why some teams are more successful than others [21]. Currently, the competitiveness of a company is mostly derived from its intangible assets rather than its tangible ones; e.g., knowledge sharing [10]. The most strategically important intangible asset in organizations is knowledge. Knowledge, if managed correctly, can provide organizations with competitive advantages over their competitors. The lack of proper knowledge sharing negatively impacts virtual teams. The growing global economy and the dependence on outsourcing are making knowledge sharing a very important factor across international boundaries and time zones. Global VTs present an increase of complexities in terms of knowledge sharing for organizations that seek to share knowledge effectively between their team members from different cultures and time zones [22]. Organizations can integrate both internal and external knowledge capacity through knowledge sharing, which can provide them with a more advantageous position in the market. Although knowledge sharing results in increased performance within companies, only a few companies have managed to implement the knowledge sharing process. Knowledge sharing can be unsuccessful due to many reasons, such as a lack of technological resources and personal motivation, difference in individual skills, and a lack of organizational support and training [23]. In the past few decades, knowledge management has received considerable attention from research due to its importance in providing companies with competitive edge. According to a study conducted by Fortune 500 companies, the estimated annual cost of knowledge loss is around 31.5 billion USD, and it is caused by the improper management of knowledge. Knowledge sharing benefits organizations by the process of transformation of individual knowledge into corporate knowledge. There are many reasons for knowledge loss, including the major ones of turnover and retirements. Knowledge sharing must be implemented correctly to ensure that the organization manages knowledge and prevents its loss successfully. Knowledge sharing is the central process that links together other knowledge management processes and practices. A lack of knowledge sharing creates difficulties for a company to take full advantage of its investments in its ability to capture and create knowledge. Knowledge sharing is the most important and complex process in knowledge management and requires a focus on three key areas, i.e., individual, organizational, and technological. The difficulty occurs due to the three dimensions being difficult to manage and their tendency to interfere with each other [24]. The individual dimension includes trust, reciprocal relationships, the intention to share knowledge, enjoyment, and personal motivation. The organizational dimension includes management support, organizational structure, organizational culture, and rewards. The technological dimension includes all information and communications technology (ICT). Knowledge is developed and communicated through social interactions between team members; even the weak social ties have an important effect on knowledge sharing. Although knowledge sharing is a valuable resource, its value depends on its quality. Knowledge quality has three dimensions, i.e., intrinsic, contextual, and actionable. Intrinsic knowledge quality is defined as the degree to which that knowledge is accurate and reliable. Contextual knowledge quality refers to the use of knowledge in professional roles and contexts. Actionable knowledge quality is the degree to which the knowledge experience is adaptable, expandable, and easily employable in tasks [25]. Individuals may not share knowledge for various reasons, an example of which could be that sharing knowledge may weaken the individual's position in the company and affect their job security or cause the loss of their unique knowledge within the organization. There is a fear of losing ownership, while no rewards exist to motivate the individual to share their knowledge. Another significant barrier for 
knowledge sharing activities is the organizational context. This barrier forms within the organization from such factors as negative organizational climate and culture, excess of authority, and the absence of communication policies and procedures. Organizations can overcome this issue by providing management support and by creating a good relationship with their employees [23]. VT performance is affected when the virtual team members hold on to their knowledge and refuse to share it. Table 1 summarizes the factors studied by the authors that affect knowledge sharing in VTs. The following key elements will be discussed in further detail below: Culture, motivation, leadership, trust, ICT, language, and conflict.

Table 1. Factors affecting knowledge sharing in virtual teams (VTs).

\begin{tabular}{ll}
\hline Factor & Authors \\
\hline Culture & {$[7,26-28]$} \\
Motivation & {$[10,29,30]$} \\
Leadership & {$[3,7,26,31,32]$} \\
ICT & {$[10,31-33]$} \\
Conflict & {$[31,34-36]$} \\
Trust & {$[6,16,31,37,38]$} \\
Language & {$[39-41]$} \\
\hline
\end{tabular}

Culture: In virtual teams. cultural diversity is believed to broaden the knowledge and perspective, thus enhancing the team's creativity. However, in some cases, it can hinder creativity. Cultural difference equals cultural identities within the team, thus creating cultural obstacles. Differences in values and norms can create intercultural difficulties, such as miscommunication and misunderstandings, which may hinder the knowledge sharing process [42]. The key barrier for knowledge sharing in virtual teams is the extent of geographical and cultural distance [30]. Although VTs provide organizations with a way to integrate skills, talent, and other assets from people across the world, the cultural differences within the team add complexity to the relationships between the team members and to the collaboration and knowledge sharing processes. Culture is the most significant boundary in virtual teams. In previous studies, two critical components were defined to differentiate between the cultures of the team members, i.e., language and the country of residence. National/cultural diversity and its effect on team performance can be placed into two categories, i.e., task-specific processes and socioemotional processes. Task-specific processes refer to the tasks that the team performs to accomplish a task or to achieve a goal. Socioemotional processes emerge when team members turn their focus towards team cohesion, building trust, and social integration [43]. Drawing on the social identity perspective, there are two types of negative social processes in multicultural teams, i.e., surface-level and deep-level cultural diversity [40]. Surface-level cultural diversity divides the team into culture-based subgroup faultiness. Faultiness culture causes two types of identity problems. Firstly, team members may experience identity threat; e.g., threat to their prestige and pride, which is caused by the presence of other cultural groups and is related to intergroup conflict. In contrast, identity fragmentation refers to the lack of cultural identity among the team members, which is less threatening but can impact team identity and lower commitment. Moreover, it is related to withdrawal behaviors. Deep-level cultural diversity triggers the negative social process. Cultural differences include values, beliefs, norms, preferences, and incompatibility assumptions, which can create difficulties in intercultural interactions; e.g., misunderstandings, miscommunication, and incompatible behaviors [42]. Cultural differences are perceived to cause an increase in the complexity of knowledge sharing, especially in the exchange of a complex idea. However, some studies have shown that cross-cultural teams affect knowledge sharing positively by making contextual and tacit knowledge more explicit [39]. Tacit knowledge is intangible and is deeply rooted in organizational practices [44]. According to the social attraction theory, diverse teams with different cultural backgrounds show low performance due to the difference in the members' attitudes, values, and beliefs [43]. Different cultural backgrounds of teams in terms of ethnicity, gender, and national culture - functionally create a context of cultural complexity, which may 
negatively affect knowledge sharing [10]. A few studies have examined the effect of cross-cultural or different nationality backgrounds on knowledge sharing in VTs [43]. Based on the above, we propose the following hypothesis: Hypothesis 1. Culture negatively affects the knowledge sharing process.

Motivation: One of the problems related to knowledge sharing is people's unwillingness to share their knowledge. This becomes more complex with added cultural diversity. Previous studies have adopted the social exchange theory to explain why people refuse to share knowledge. Accordingly, they have qualified two types of motivation: Intrinsic and extrinsic motivation [29]. Social identity theory is defined as "that part of an individual's self-concept which derives from their knowledge of their membership in a social group together with the value and emotional significance attached to that membership." Identity shapes the perception of team members and provides meaning for one's actions. According to the social identity theory, individuals use central, useful, and relevant categories to categorize their identities; e.g., belonging to a national culture. In social interactions, people usually represent their teams. Social ties within teams are interpersonal and can generate more competitiveness between subgroups. These interpersonal differences can fragment the team into subgroups, which may result in a negative effect on the team's performance. Knowledge sharing is subject to the dynamics of these identifications that create the subgroups. Many studies concluded that national culture drives social identification [30]. Intrinsic and extrinsic factors have been shown to have a positive impact on knowledge sharing. Altruistic individuals are more willing to share knowledge with their team members. Moreover, explicit knowledge facilitates knowledge sharing. Conversely, tacit knowledge creates barriers. Sharing tacit knowledge within the project team is vital for achieving success [10]. Extrinsic motivation is related to the economic and social rewards [29]. Reciprocal benefits and financial rewards are extrinsic. Team members who perceive reciprocal benefits from sharing knowledge are more likely to be involved in the knowledge sharing process, as it is beneficial for them. Moreover, it creates indebtedness among team members. A study done in multicultural companies revealed that people from strong sharing cultures were motivated to share knowledge out of reciprocity. Research into the effect of reciprocity on knowledge sharing is scarce [22]. Extrinsic rewards have been shown to have a negative impact on knowledge sharing [10]. Intrinsic motivators include self-efficacy and enjoyment [29]. Enjoyment positively affects knowledge sharing in VTs [22]. A lack of motivation in employees inhibits their sense of self-efficacy, which results in obstruction of knowledge sharing. When an organization provides its employees with support, their self-efficacy increases, which in turn leads to more knowledge sharing behavior [23]. Recognizing, rewarding, or punishing employees using the process of motivation are directly related to cultural values [41]. Based on the above, we propose the following hypothesis (we examine Intrinsic Motivation (Self-Efficacy and Enjoyment) and Extrinsic Motivation (Rewards and Reciprocal Benefits)): Hypothesis 2. Motivation (intrinsic and extrinsic) positively affects knowledge sharing in virtual teams.

Language: Another variable that affects team knowledge sharing and one that has been named the missing factor is language [39]. Language is one of the most significant barriers and the fundamental cause of problems in cross-cultural communication. Language, including social norms and social interaction, differs from one culture to another [41]. Language certification is becoming an admission condition, rather than a graduation requirement. However, the interaction that is delivered by a course and provided by case studies is only indirect, and not the interaction itself. The soft skills required by managers, such as cultural intelligence and agility, require first-hand experience. Companies are using international assignments to develop their managers' competencies [40]. Indirect experience of culture prevents the individuals from sharing their ideas with other team members, thus preventing the integration of ideas with other cultures [42]. It has been shown that sharing a common language increases the communication and knowledge sharing activities among team members. Language commonality refers to the degree to which the individuals share the same understanding of a language; for example, the English language. This understanding covers the proficiency of language use, including the overlapping knowledge and styles of communication. Where a lack of language commonality is present, rich media may further complicate the communication and knowledge sharing, whereas in 
non-rich media, such as email, people have the option to use a spell-checker and review the text before sending it [39]. We propose the following hypothesis to test the effect of language on knowledge sharing: Hypothesis 3. Language negatively affects knowledge sharing in virtual teams.

Conflict: People working together hold different perceptions, opinions, and values, and also communicate differently. This may cause conflict to occur. The reason for this difference is that our values, norms, and social interactions are culture-based and programmed into our minds to process the behaviors of others according to our culture's values and beliefs. In culturally diverse team interactions, each member may misinterpret the other's intentions or perceive their behavior and motives as a threat, which may cause conflict to occur between the team members [41]. The following definition of team conflict is given: "Conflict will refer to situations that occur when two or more people working within the same organization perceive differences in beliefs, values, or goals which impact their ability to work together and/or affect the work environment." Conflict is categorized into three categories: Task, relationship, and process conflict. Task conflict refers to the group's tasks, including viewpoints, task awareness, and difference in opinions. Relationship conflict refers to disagreement over work-unrelated issues, i.e., social or personal. Process conflict refers to the conflict that may occur from disagreement over procedure, task strategy, delegation of duties, and team resources [35]. There are many reasons for difficulty in VT knowledge sharing, such as identity threat, which emerges from the formation or creation of subgroups. The number of identities in teams is increased due to such globalization trends like outsourcing of knowledge, which is related to the different cultures, backgrounds, nationalities, professional tenure, and degree of experience in specific industries of the employees. These differences in identity shape subgroups, which in turn create conflict between those subgroups. The conflict arises from status differences that threaten their subgroup identity [36]. We can conclude that conflict negatively affects the knowledge sharing process: Hypothesis 4. Conflict negatively affects the knowledge sharing process.

ICT usage: Information and communications technology helps to facilitate the process of knowledge sharing between employees within an organization. However, it does not eliminate the need for collaboration between the employees. ICT acts as a catalyst in organizational learning. Consequently, an organization that is actively learning possesses a competitive advantage. One of the most difficult challenges that managers face in establishing learning in their organizations is knowledge sharing because knowledge can be neither forced nor controlled. Managers need to find a way to motivate their employees to share and transfer their knowledge. Researchers have identified that the likelihood of knowledge sharing to occur between two parties depends on the strength (strong or weak) and quality (positive or negative) of their relationship. ICT acts as a socio-technical system that allows employees to interact using different devices, such as voice-mail, email, video conferencing, intranet, wikis, etc. [45]. For virtual teams, the use of media for communication is a problem. Selecting media within culturally diverse teams is a problem. Different values and perceptions inherent in different cultures may cause slow acceptance of or different preferences in using one communication medium over another. For example, some cultures may process information differently, giving higher or lower priority to some tasks and experiencing different levels of satisfaction in using various ICT tools [41]. ICT has been shown to have positive impact on the knowledge sharing process [10]. Lean media increase team conflicts and social fragmentation in multicultural teams [39]. Technology used by virtual teams is very important for team communication. Media richness has been found to increase team efficiency, effectiveness, and the relationships between the team members, as well as their commitment [20]. Cultures exhibiting uncertainty avoidance are less likely to use electronic media, since such media do not cover ways to avoid uncertainty; e.g., face-to-face communication. The use of ICT in individualistic cultures lessens the majority influence, while the majority influence in collectivistic cultures remains prevalent. One way to overcome this is to use content anonymity, since anonymity allows people from socialist cultures to express their ideas clearly. In a power distance culture, levelling effects occurred in a high power distance, while no effect was recorded in a low power distance [41]. Effective use of ICT positively affects team performance and removes the negative 
effects of cultural diversity [20]. The following hypothesis is suggested to be tested: Hypothesis $\mathbf{5}$. ICT positively affects knowledge sharing in VTs.

Trust: One of the most important factors that affects team performance is trust. Physical diaspora, different cultural backgrounds, and changes of team members have made trust more difficult to achieve between the team members. In a trusting relationship, people are willing to be traded on in return for the collective benefits of the team. Developing trust mainly relies on the members' cultural background [46]. Unlike traditional teams that develop trust by interacting face to face, VTs develop trust by sharing timely and appropriate responses through ICT and are engaged in task-based relationships [43]. Trust is a key factor in relationships between team members, which makes it the most determinant factor in team knowledge sharing. Trust is vital, since it helps to reduce the psychological distance between the team members [38]. When team members trust their partners, the social ties are strong and the contribution to sharing knowledge is increased. [10]. There are three types of trust: Calculus-based trust, knowledge-based trust, and identity-based trust. The initial establishment of trust is very important in the establishment of knowledge-based trust. Trust is fragile within the VT. According to the social exchange theory, once swift trust is established, trust depends on the knowledge gained from team members as well as on the positive and negative events that have occurred or may occur [21]. In a trusting environment, people tend to believe that their behaviors will lead to favorable results. When team members trust each other, there is a sense of obligation to share knowledge; in order to not break the obligation, they are likely to be more motivated to share knowledge [47]. The following three antecedents for trust are taken into consideration: Ability, benevolence, and integrity. Ability refers to the trust in the skills and competencies of the leader. Benevolence refers to the intentions and motives of the trusted person. Integrity refers to the principles governing the conduct of the trusted person [38]. Trust differs between face-to-face interactions and virtual teams. In collocated environments where team members communicate face to face, trust tends to increase with time, whereas in virtual settings, there is a high level of initial trust, but with time, this trust can either decrease or increase [21]. Trust and knowledge sharing are related. However, few studies have analyzed the impact that trust between team members has on knowledge sharing. We can conclude as a hypothesis that trust has an effect on knowledge sharing: Hypothesis 6. Trust positively affects knowledge sharing in virtual teams.

Leadership: Another important factor for ensuring the success of a team is leadership. In VTs, the leader is a virtual leader that uses ICT to communicate with their team members. There is a great effort required of such a leader to manage team tasks, build relationships, and facilitate the team process [38]. The lack of collocated interaction between team members creates many challenges that may affect knowledge sharing and performance of the virtual team. Some of these challenges are trust, conflict management, decision-making, and expressing opinions. Leadership can overcome these challenges [48]. Leadership plays an important role in overcoming challenges that afflict virtual teams and helps them to realize their full potential [19]. Developing trust is an essential characteristic of VT leaders [11]. A few studies have explored successful factors that affect team creativity. Even in a virtual setting, team creativity necessitates several preconditions; e.g., a psychologically safe environment and the empowerment to share among the team members. A psychologically safe environment refers to team members working together, valuing each other's knowledge, sharing information, and discussing mistakes without the fear of being penalized. Leadership fosters creativity by providing psychological safety [49]. Leaders who draw clear distinctions between reward and penalty with regards to the team behavior of their subordinates can encourage the employees to be more willing to share their knowledge [10]. One of the most difficult challenges that managers face in establishing learning in their organizations is knowledge sharing because knowledge can be neither forced nor controlled. Leaders need to find a way to motivate their employees to share and transfer their knowledge. Researchers have identified that the likelihood of knowledge sharing to occur between two parties depends on the strength (strong or weak) and quality (positive or negative) of their relationship. ICT acts as a socio-technical system that allows employees to interact using different devices, such as voice-mail, 
email, video conferencing, intranet, wikis, etc. [45]. All these benefits are subject to the virtual teams being managed well. The effectiveness of leadership plays a key role in the success of virtual teams. Similarly to in face-to-face teams, the development of relationships within virtual teams is natural and organic. To be successful, leaders must be culturally literate and proficient in a language to do global business [40]. The following hypothesis is proposed: Hypothesis 7. Leadership positively affects knowledge sharing in virtual teams.

As a conclusion, scholars who are experts in the VT field suggested the following factors to have significant impact on VTs' knowledge sharing: Culture, motivation, leadership, trust, ICT, language, and conflict. Thus, after identifying these factors and formulating hypotheses, the next step is to empirically test the significance of such hypotheses.

\subsection{Research Model}

In order to test our Model presented in Figure 1 answer these research questions, we conducted empirical research to study the impact of culture, motivation, leadership, trust, ICT, language, and conflict on VT knowledge sharing, since these factors are the most cited and emphasized by the expert authors in the field of VTs. We prepared a research instrument (a questionnaire) comprised of 48 questions by analyzing the available literature. Eight questions are related to the participant's demographic details; five questions relate to each factor. The questions in the questionnaire were compiled from the review of articles written by experts in the ICT field. The questions were chosen using tested hypotheses. The method used to collect the data is Google Forms. An email was sent to the participants with a link to the questionnaire. No incentive was offered to answer the questions. Three follow-up emails were sent to the participants to complete the questionnaire. We used the Structural Equation Modeling (SEM) technique and AMOS 23.0 to test the following hypotheses:

Hypothesis 1. Culture positively affects the knowledge sharing process.

Hypothesis 2. Motivation (intrinsic and extrinsic) positively affects knowledge sharing in virtual teams.

Hypothesis 3. Language negatively affects knowledge sharing in virtual team.

Hypothesis 4. Conflict negatively affects the knowledge sharing process.

Hypothesis 5. ICT positively affects knowledge sharing in VTs.

Hypothesis 6. Trust positively affects knowledge sharing in virtual teams.

Hypothesis 7. Leadership positively affects knowledge sharing in virtual teams.

For the data sample, we selected participants who are members of virtual teams in the IT industry in the United Arab Emirates (UAE). The target organizations are three IT service companies that provide consultancy services in enterprise resource planning (ERP), business intelligence (BI), and expert knowledge in information and communications technology (ICT). The three companies have multiple brunches worldwide, and their teams communicate using ICT. The data collected are from the UAE. The questionnaires were sent to 747 employees. There were 203 respondents to the survey.

We used the Cronbach Alpha method to assess the reliability of the questions used for measurement. Acceptable values should be above 0.7 to reflect the acceptable reliability. The considered variables all exceed the 0.7 value. We used confirmatory factor analysis (CFA) to determine the dimensional structure of the scale based on eigenvalues greater than 1 . We used the maximum likelihood method, as it was the best method to determine the parameters of distribution and to describe the given data. 


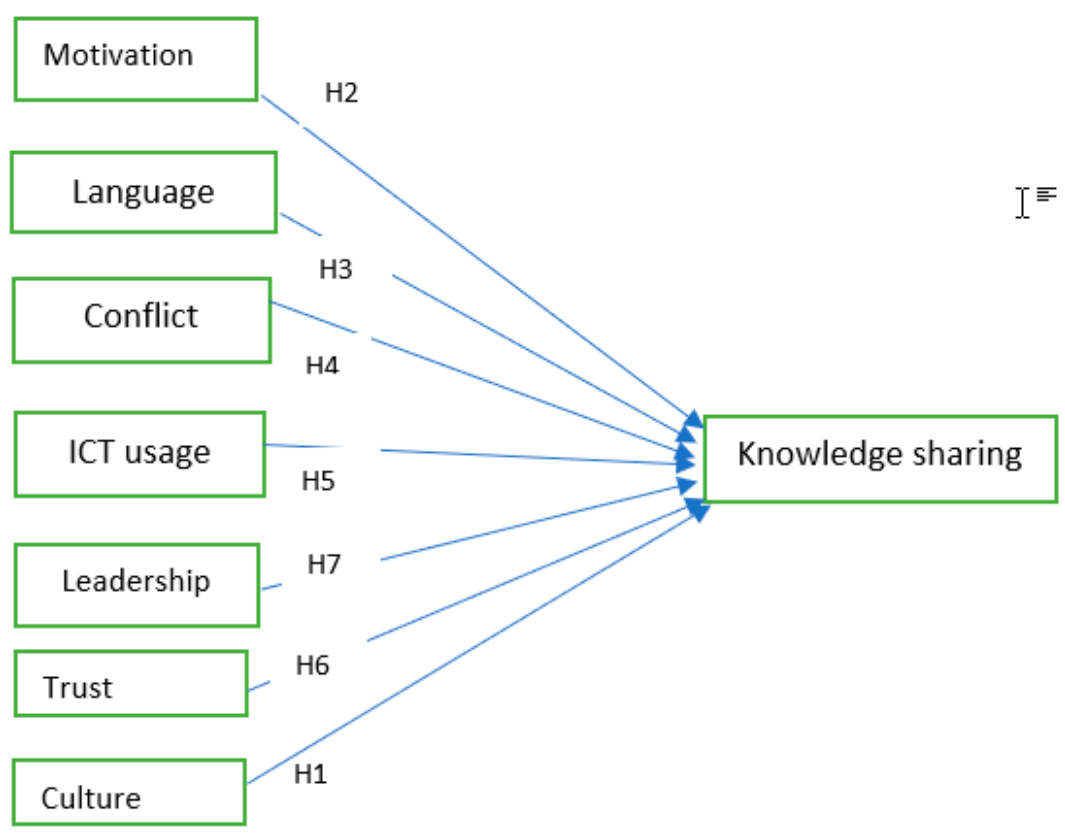

Figure 1. Knowledge sharing measurement model.

\section{Results and Discussion}

The respondent sample consisted of 156 males (76.84\%) and 47 females (23.16\%). A total of 152 respondents $(74.87 \%)$ use both online and face-to-face communication techniques when interacting with other teams; 20 respondents $(9.85 \%)$ communicate only face-to-face; and 31 respondents $(31 \%)$ use online communication with virtual teams. A total of $92.11 \%$ of the respondents (187) are team members and $7.89 \%$ of the respondents (16) are team leaders. A total of 70 respondents $(34.48 \%)$ are in the age group 22-29; 124 respondents (61.08\%) are in the age group 30-49; and $4.44 \%$ (9) of the respondents are aged 50+. A total of $23.15 \%$ (47) of the respondents have less than one year of experience in VTs; $42.03 \%$ (85) have 1-5 years of experience; $24.63 \%$ (50) have 6-10 years of experience working in VTs; and $8.18 \%$ (21) have worked in VTs for over ten years. The following are the time frames for which the respondents have been members of their current VTs: 56 respondents have been part of their current teams for less than one year; 102 respondents $-1-5$ years; and 45 respondents have been members of their current VTs for over five years. The following are the numbers of members in teams according to the responses: Less than 10 members in a team $-32 \%$; $10-50$ members- $44 \%$; more than 50 members $-24 \%$. The following are the types of services that the companies provide according to the responses: $37.5 \%$ of companies provide ERP services; $28.4 \%$ - BI services; and $65.9 \%$ provide both types of services, as presented in Table 2 below.

To contrast the proposed hypotheses, we developed the structural equations model shown in Figure 2 and examined the effect of each factor on knowledge sharing. This study seeks to examine the factors that affect knowledge sharing within virtual teams. We used the Structural Equation Modeling (SEM) technique and AMOS 23.0 to test the research question of the study. We used maximum likelihood. To validate the measurement model, we assessed its convergent and discriminant validity. The following questions were removed to increase the internal consistency of the model: conflict1, culture5, technology5, language5, motivation5, knowledgesharing3, knowledgesharing2, and trust5.

The standardized path loadings of all items were significant and exceeded 0.5. The composite reliability (CR) exceeded 1.96, and the average variance extracted (AVE) exceeded 0.5. Therefore, convergent validity was supported. We calculated the maximum squared variance and found that it was less than the AVE, thus supporting the discriminant validity. Moreover, the multicollinearity test showed that the correlation between independent variables is less than 0.3 ; hence, there were no multicollinearity issues. 
Table 2. Demographics.

\begin{tabular}{ll}
\hline \multicolumn{1}{c}{ Details } & Percentage \\
\hline Gender & Male: 76.84 \\
& Female: 23.16 \\
\hline Mode of Communication & Online: 31 \\
& Face-to-face: 9.85 \\
& Both online and face-to-face: 74.87 \\
\hline Designation & Team member: 92.11 \\
& Team leader: 7.89 \\
\hline Age & $22-29: 34.48$ \\
& $30-49: 61.08$ \\
& $>50: 4.44$ \\
\hline Work experience in years as a virtual team member & $<1: 23.15$ \\
& $<1$ and $<5: 42.03$ \\
& $<5$ and $<10: 24.63$ \\
& $>10: 8.18$ \\
\hline Work experience in years in the current virtual team & $<1: 27$ \\
& $<1$ and $<5: 50$ \\
& $>5: 23$ \\
\hline Number of members in a team & $<10: 32$ \\
& $10-50: 44$ \\
& $>50: 24$ \\
\hline Service provided by the company & ERP: 37.5 \\
& BI: 28.4 \\
& Both: 65.9 \\
\hline
\end{tabular}

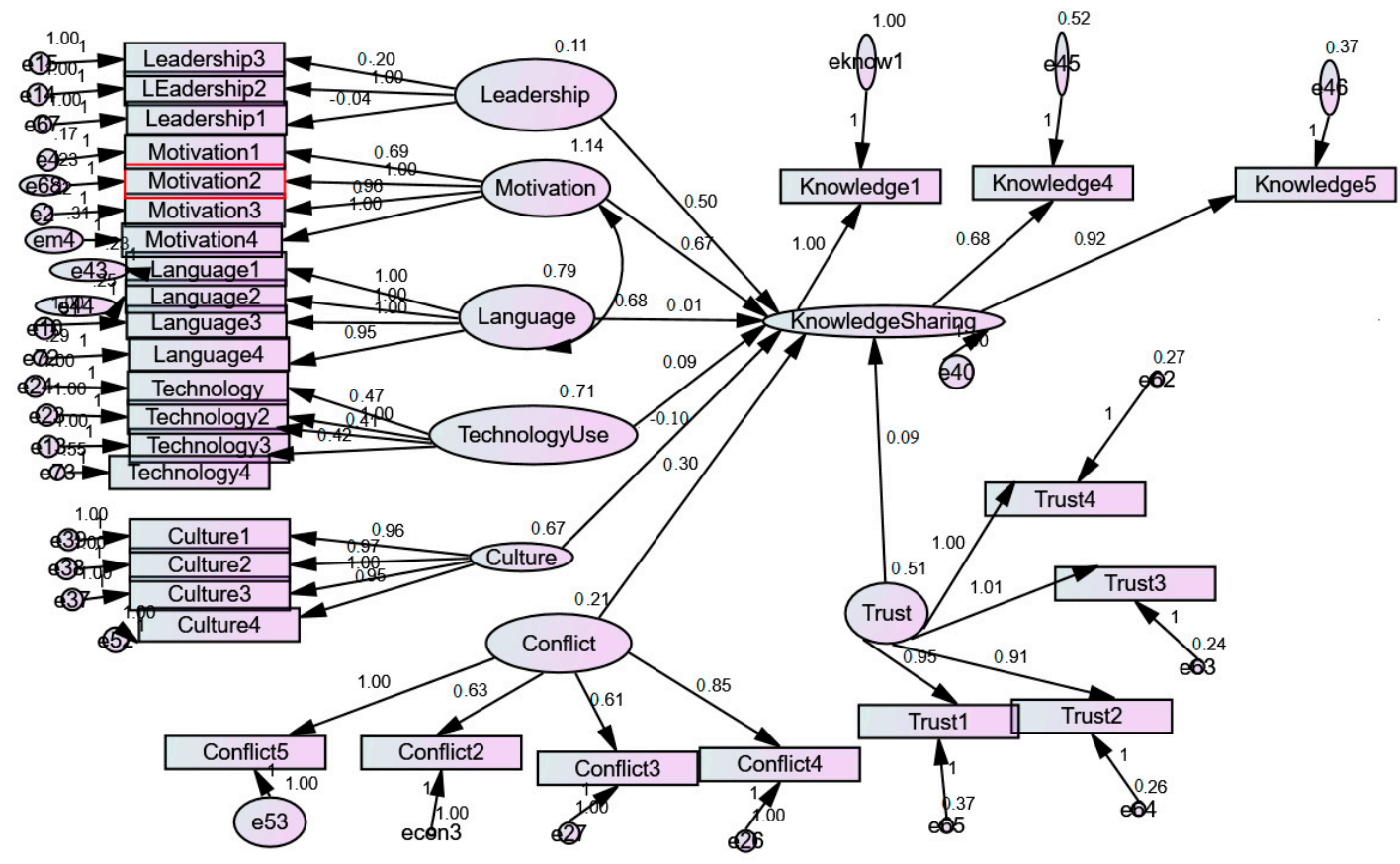

Figure 2. Structural model for knowledge sharing.

The model fit also verified the results for the Comparative Fit Index (CFI), Standardized Root Mean Square Residual (SRMR), Root Mean Square Error of Approximation (RMSEA), and PClose (p of close fit this measure, is a one-sided test of the null hypothesis, which indicates close-fitting model); these were acceptable results, as shown in Table 3. In Table 3, the fit indices for the structural equation model are shown; chi-square, which is called CMIN, divided by degree of freedom (DF), is 2.87 and falls between 1 and 3. Comparative Fit Index (CFI) is 0.93 and falls above 0.90, and Standardized Root Mean Square Residual (SRMR) and Root Mean Square Error of Approximation (RMSEA) are below the 
threshold, as shown in Table 3. PClose, which tests for close fit, is 0.06 and falls above the threshold of 0.05; this results in model fit.

Table 3. Model fit.

\begin{tabular}{llll}
\hline Measure & Estimate & Threshold & Interpretation \\
\hline CMIN & 1934.38 & - & - \\
DF & 674 & - & - \\
CMIN/DF & 2.87 & Between 1 and 3 & Acceptable \\
CFI & 0.93 & $>0.90$ & Acceptable \\
SRMR & 0.067 & $<0.08$ & Acceptable \\
RMSEA & 0.056 & $<0.06$ & Acceptable \\
PClose & 0.06 & $>0.05$ & Acceptable \\
\hline
\end{tabular}

As shown in Table 4, the results indicate that Culture (H1) has a composite reliability (CR) of -3.711 , an estimate of -0.101 , a standard error (SE) of 0.029 , and a $p$-value of less than 0.001 . This means that the regression weight for Culture in the prediction of knowledge sharing is significantly different from zero at the 0.05 level (two-tailed). In other words, H1 is significant. Motivation (H2) has a composite reliability (CR) of 15.433, an estimate of 0.667 , a standard error (SE) of 0.041 , and a $p$-value of less than 0.001 . This means that the regression weight for Motivation in the prediction of knowledge sharing is significantly different from zero at the 0.05 level (two-tailed). In other words, $\mathrm{H} 2$ is significant. Language (H3) has a composite reliability (CR) of 0.791 , an estimate of 0.12 , a standard error (SE) of 0.37 , and a $p$-value of 0.429 . This means that the regression weight for Language in the prediction of knowledge sharing is not significantly different from zero at the 0.05 level (two-tailed). In other words, H3 is not significant. Conflict (H4) has a composite reliability (CR) of -3.510, an estimate of -0.304 , a standard error (SE) of 0.086 , and a $p$-value of less than 0.001 . This means that the regression weight for Conflict in the prediction of knowledge sharing is significantly different from zero at the 0.05 level (two-tailed). In other words, H4 is significant. ICT (H5) has a composite reliability (CR) of 3.079, an estimate of 0.092 , a standard error (SE) of 0.032 , and a $p$-value of less than 0.002 . This means that the regression weight for ICT in the prediction of knowledge sharing is significantly different from zero at the 0.05 level (two-tailed). In other words, $\mathrm{H} 5$ is significant. Trust (H6) has a composite reliability (CR) of 3.187, an estimate of 0.09 , a standard error (SE) of 0.29 , and a $p$-value of 0.001 . This means that the regression weight for Trust in the prediction of knowledge sharing is significantly different from zero at the 0.05 level (two-tailed). In other words, H6 is significant. Leadership (H7) has a composite reliability (CR) of 2.59, an estimate of 0.505 , a standard error (SE) of 0.196 , and a $p$-value of 0.01 . This means that the regression weight for Leadership in the prediction of knowledge sharing is significantly different from zero at the 0.05 level (two-tailed). In other words, H7 is significant.

Table 4. Standardized regression weights.

\begin{tabular}{llllllll}
\hline Hypothesis & DV & IV & Estimate & $\begin{array}{l}\text { Standard } \\
\text { Error }\end{array}$ & $\begin{array}{l}\text { Composite } \\
\text { Reliability }\end{array}$ & $p$-Value & Result \\
\hline H1 & KnowledgeSharing & Culture & -0.101 & 0.029 & -3.711 & $* * *$ & Supported \\
H2 & KnowledgeSharing & Motivation & 0.667 & 0.041 & 15.433 & $* * *$ & Supported \\
H3 & KnowledgeSharing & Language & 0.012 & 0.37 & 0.791 & 0.429 & Not Supported \\
H4 & KnowledgeSharing & Conflict & -0.304 & 0.086 & -3.510 & $* * *$ & Supported \\
H5 & KnowledgeSharing & ICT & 0.092 & 0.032 & 3.079 & 0.002 & Supported \\
H6 & KnowledgeSharing & Trust & 0.09 & 0.029 & 3.187 & 0.001 & Supported \\
H7 & KnowledgeSharing & Leadership & 0.505 & 0.196 & 2.590 & 0.010 & Supported \\
\hline
\end{tabular}

*** indicate value less than 0.001 .

We tested the model by collecting the data through an online survey and used the AMOS SPSS software. As shown in Table 4, the results indicate that Culture (H1), Motivation (H2), Conflict (H4), ICT (H5), Trust (H6), and Leadership (H7) are supported, which corresponds with the literature discussion. 
When employees use ICT and are more collaborative, the knowledge sharing process is enhanced and facilitated. When there is an increase in trust, the employees are more willing to share their knowledge with other team members. The increase of the number of different cultures in a VT causes cultural identities within the team and creates cultural obstacles, which negatively affect knowledge sharing in a VT. Conflict is one the main reasons hindering the knowledge sharing process. When conflict is present, team members are unwilling to share their knowledge with their team members. Team leaders must solve the conflict between the team members and motivate them to share knowledge. However, Language (H3) was not supported and showed no effect on knowledge sharing, unlike what the existing literature suggests, wherein some researchers find direct consequence between language and knowledge sharing. This may be accounted for by the fact that the UAE has a wide expat diaspora from different countries speaking different languages and working together, so employees are accustomed to a variety of languages. Teams in UAE companies are composed of team members who are from different nationalities and who speak different languages, so members are used to dealing with other members with different languages. Hence, this is also reflected when dealing with online members. There are several key findings in our analysis of the factors affecting knowledge sharing. We have found that Culture, Motivation, Conflict, ICT, Trust, and Leadership all affect knowledge sharing and have a significant $p$-value of $<0.05$, using a $95 \%$ confidence interval, whereas Language is not significant, as is shown in Table 4. With the increase in Motivation, ICT, Trust, and Leadership, knowledge sharing in the organization also increases. Conversely, the increase in Conflict and Cultural Diversity causes knowledge sharing to decrease. This is very beneficial for organizations with regards to building strong teams that have the capability and the willingness to share knowledge, which results in effective virtual teams. The managers of existing virtual teams can measure the level of knowledge sharing and work to better the weak aspects, which in turn enhances the knowledge sharing process within the team. For example, if conflict or cultural diversity are high, they need to find a way to reduce the degree to which conflict or culture hinder knowledge sharing. When hiring new team members, organizations must take into consideration those factors and hire individuals that are potentially cohesive with the existing team members. This model forms a basis for organization in developing countries and can be used to build upon when measuring virtual team performance; it can be further integrated with new models that propose implementation plans designed to establish high-performance VTs. Our findings in the UAE are comparable to the studies conducted in Europe and the U.S. in terms of the following factors: Culture, motivation, conflict, ICT, trust, and leadership. However, language in Europe and the U.S. has been shown to have a significant effect on VT knowledge sharing, whereas no significant effect was found in the UAE.

As all research has limitations, the limitations of this article are as follows: The first limitation of this study is that seven factors affecting knowledge sharing were used; however, there are other factors that affect knowledge sharing, but were not included in this study; secondly, the study was conducted in the industry of IT organizations, and future studies should include other industries; thirdly, this study was conducted in the UAE, and future studies should include other countries.

This study has several implications for research, as it is the first one to study the following seven factors that affect knowledge sharing in a developing country together, i.e., culture, motivation, language, conflict, ICT, trust, and leadership. Promoting and encouraging knowledge sharing in organizations remains a challenge for organizations. It is important for organizations to develop a strategy that promotes knowledge sharing in the organization. This requires organizations to understand the factors that affect knowledge sharing. As demonstrated in this study, the elements or factors that affect knowledge sharing are culture, motivation, language, conflict, ICT, trust, leadership, and collaboration. Organizations must implement strategies that eliminate the effects of different cultures and minimize conflict as well as promote motivation with rewards, collaboration, and trust between team members. Leadership should be the source of an example for knowledge sharing. 


\section{Conclusions}

The increased use of ICT and its rapid development have significantly impacted the establishment of virtual teams. One of the most important competitive advantages is the intellectual one that can be created, shared, and disseminated between team members. It is especially relevant for dispersed teams whose members come from different backgrounds and cultures and hold different points of view. Even though there is a lot of research done on VTs, there is little on the VT knowledge sharing within organizations in developing countries. In previous research, these factors of culture, motivation, leadership, trust, ICT, language, and conflict were not studied together to measure their effects on knowledge sharing, especially in developing countries.

The model proposed in this article is useful for managers to measure knowledge sharing in their virtual teams by measuring the factors provided in the model that affect the knowledge sharing process. This study recognizes the opportunities and challenges of measuring knowledge sharing in virtual teams.

The results show that knowledge sharing in virtual teams is positively correlated with motivation, ICT, trust, and leadership, while being negatively correlated with culture and conflict. There is no correlation with language. Language is the factor found to be different between the U.S., Europe, and the Middle East; it affects VT knowledge sharing in both the U.S. and Europe, while it has no effect in the Middle East.

Top management should consider such factors as ICT, trust, leadership, culture, and conflict in order to achieve an acceptable level of knowledge sharing. Management of these factors helps the organization and the team members to achieve effectiveness and efficiency, and to reach high VT performance, which in turn creates competitive advantage. Enhancing these factors results in better knowledge sharing between VT members. Managers must take into consideration the factors that positively and negatively affect the knowledge sharing process; they must try to reduce the negative factors hindering knowledge sharing between team members as much as possible, as well as promote the factors (e.g., trust) that enhance knowledge sharing in virtual teams.

As a limitation of this study is considered the evaluation of seven factors affecting knowledge sharing, and a proposal for further research is to extend research with additional factors as well as to include other industries and more developing countries.

This study proposes a framework for future studies that can add factors to this model and create new models not only for measuring, but also for the implementation of strategies that can be used to enhance knowledge sharing in virtual teams.

Author Contributions: Conceptualization, V.D. and K.A.M.; methodology, K.A.M. and V.D.; software, K.A.M.; validation, V.D. and I.M.-K.; formal analysis, I.M.-K.; investigation, K.A.M.; resources, K.A.M.; writing-original draft preparation, V.D.; writing—review and editing, V.D. and I.M.-K.; visualization, K.A.M. and I.M.-K.; supervision, V.D. All authors have read and agreed to the published version of the manuscript.

Funding: This research received no external funding.

Conflicts of Interest: The authors declare no conflict of interest

\section{References}

1. Al Majzoub, K.; Davidavičienè, V. Organization Behavior Changes Caused By Information and Communication Technologies. In Proceedings of the 10th International Scientific Conference, Vilnius, Lithuania, 3-4 May 2018. [CrossRef]

2. Azhar, S.; Ahmad, I. Introduction to the Special Issue on Information and Communication Technology (ICT) in AEC Organizations: Assessment of Impact on Work Practices, Project Delivery, and Organizational Behavior. J. Manag. Eng. 2015, 31, A2014001. [CrossRef]

3. Al Zain, N.L.; Vasilache, S.; Incze, C.B. The significance and managerial challenges of virtual teamworking. Proc. Int. Conf. Bus. Excell. 2018, 12, 25-33. [CrossRef]

4. Alsharo, M.; Gregg, D.; Ramirez, R. Virtual team effectiveness: The role of knowledge sharing and trust. Inf. Manag. 2017, 54, 479-490. [CrossRef] 
5. Schmidtke, J.M.; Cummings, A. The effects of virtualness on teamwork behavioral components: The role of shared mental models. Hum. Resour. Manag. Rev. 2017, 27, 660-677. [CrossRef]

6. Bhat, S.K.; Pande, N.; Ahuja, V. Virtual Team Effectiveness: An Empirical Study Using SEM. Procedia Comput. Sci. 2017, 122, 33-41. [CrossRef]

7. Gibbs, J.L.; Sivunen, A.; Boyraz, M. Investigating the impacts of team type and design on virtual team processes. Hum. Resour. Manag. Rev. 2017, 27, 590-603. [CrossRef]

8. Goettsch, K.L. Working with global virtual teams: A case study reality check on intercultural communication best practices. Glob. Adv. Bus. Commun. 2016, 5. Available online: http://commons.emich.edu/gabc/vol5/iss1/3 (accessed on 22 February 2020).

9. Havakhor, T.; Sabherwal, R. Team Processes in Virtual Knowledge Teams: The Effects of Reputation Signals and Network Density. Manag. Inf. Syst. 2018, 35, 266-318. [CrossRef]

10. Navimipour, N.J.; Charband, Y. Knowledge sharing mechanisms and techniques in project teams: Literature review, classification, and current trends. Comput. Hum. Behav. 2016, 62, 730-742. [CrossRef]

11. Christensen, P.H.; Pedersen, T. The dual influences of proximity on knowledge sharing. Knowl. Manag. 2018, 22, 1782-1802. [CrossRef]

12. Panteli, N.; Yalabik, Z.Y.; Rapti, A. Fostering work engagement in geographically-dispersed and asynchronous virtual teams. Inf. Technol. People 2019, 32, 2-17. [CrossRef]

13. Dong, W.; Ehrlich, K.; Macy, M.M.; Muller, M. Embracing Cultural Diversity: Online Social Ties in Distributed Workgroups. In Proceedings of the 19th ACM Conference Computer Cooperative Work \& Social Computing-CSCW'16, New York, NY, USA, 2016; pp. 273-286. Available online: http://dl.acm.org/citation. cfm?doid=2818048.2835198 (accessed on 12 February 2020).

14. Adamovic, M. An employee-focused human resource management perspective for the management of global virtual teams. J. Hum. Resour. Manag. 2018, 29, 2159-2187. [CrossRef]

15. Maduka, N.S.; Edwards, H.; Greenwood, D.; Osborne, A.; Babatunde, S.O. Analysis of competencies for effective virtual team leadership in building successful organisations. Benchmarking 2018, 25, 696-712. [CrossRef]

16. Kyu, C.O.; Cho, E. The Mechanism of Trust Affecting Collaboration in Virtual Teams and the Moderating Roles of the Culture of Autonomy and Task Complexity. Comput. Hum. Behav. 2018, 91, 305-315. Available online: https://linkinghub.elsevier.com/retrieve/pii/S0747563218304734 (accessed on 1 February 2020).

17. Aldea, C.C.; Popescu, A.D.; Draghici, A.; Draghici, G. ICT Tools Functionalities Analysis for the Decision Making Process of Their Implementation in Virtual Engineering Teams. Procedia Technol. 2012, 5, 649-658. Available online: http://linkinghub.elsevier.com/retrieve/pii/S2212017312005038 (accessed on 14 February 2020). [CrossRef]

18. Laitinen, K.; Valo, M. Meanings of communication technology in virtual team meetings: Framing technology-related interaction. Hum. Comput. Stud. 2018, 111, 12-22. [CrossRef]

19. Liao, C. Leadership in virtual teams: A multilevel perspective. Hum. Resour. Manag. Rev. 2017, $27,648-659$. [CrossRef]

20. Pinjani, P.; Palvia, P. Trust and knowledge sharing in diverse global virtual teams. Inf. Manag. 2013, 50, 144-153. [CrossRef]

21. Jaakson, K.; Reino, A.; McClenaghan, P.B. The space between-Linking trust with individual and team performance in virtual teams. Team Perform. Manag. 2018. [CrossRef]

22. Killingsworth, B.; Xue, Y.; Liu, Y. Factors influencing knowledge sharing among global virtual teams. Team Perform. Manag. 2016, 22, 284-300. [CrossRef]

23. Lekhawipat, W.; Wei, Y.H.; Lin, C. How internal attributions affect knowledge sharing behavior. Knowl. Manag. 2018, 22, 867-886. [CrossRef]

24. Abdelwhab, A.A.; Selvam, D.P.; Paris, L.; Gunasekaran, A. Key factors influencing knowledge sharing practices and its relationship with organizational performance within the oil and gas industry. Knowl. Manag. 2019, 23, 1806-1837. [CrossRef]

25. Olaisen, J.; Revang, O. Working smarter and greener: Collaborative knowledge sharing in virtual global project teams. Inf. Manag. 2017, 37, 1441-1448. [CrossRef]

26. Derven, M. Four drivers to enhance global virtual teams. Ind. Commer. Train. 2016, 48, 1-8. [CrossRef]

27. Gao, S.; Guo, Y.; Chen, J.; Li, L. Factors affecting the performance of knowledge collaboration in virtual team based on capital appreciation. Inf. Technol. Manag. 2016, 17, 119-131. [CrossRef] 
28. Li, Y.; Rau, P.L.; Li, H.; Maedche, A. Effects of a dyad's cultural intelligence on global virtual collaboration. IEEE Trans. Prof. Commun. 2017, 60, 56-75. Available online: https://ieeexplore.ieee.org/document/7828155 (accessed on 12 March 2020). [CrossRef]

29. Zhang, X.; De Pablos, P.O.; Xu, Q. Culture effects on the knowledge sharing in multi-national virtual classes: A mixed method. Comput. Hum. Behav. 2014, 31, 491-498. [CrossRef]

30. Ambos, T.C.; Ambos, B.; Eich, K.J.; Puck, J. Imbalance and Isolation: How Team Configurations Affect Global Knowledge Sharing. Int. Manag. 2016, 22, 316-332. [CrossRef]

31. Plotnick, L.; Hiltz, S.R.; Privman, R. Ingroup Dynamics and Perceived Effectiveness of Partially Distributed Teams. IEEE Trans. Prof. Commun. 2016, 59, 203-229. [CrossRef]

32. Acai, A.; Sonnadara, R.R.; O'Neill, T.A. Getting with the times: A narrative review of the literature on group decision making in virtual environments and implications for promotions committees. Perspect. Med. Educ. 2018, 7, 147-155. Available online: http://link.springer.com/10.1007/s40037-018-0434-9 (accessed on 17 March 2020). [CrossRef]

33. Pozin, M.A.A.; Nawi, M.N.M.; Romle, A.R. Effectiveness of virtual team for improving communication breakdown in IBS project delivery process. Int. J. Supply Chain Manag. 2016, 5, 121-130. Available online: https:/www.scopus.com/inward/record.uri?eid=2-s2.0-85009431569\&partnerID=40\&md5= 31df8761f94fb6eb37b76d479069924d (accessed on 5 April 2020).

34. Cordes, S.; Cordes, S. Knowledge Management \& E-Learning and technology affordance in team decision making and technology affordance in team decision making. Knowl. Manag. E-Learn. 2016, 8, 602-627. [CrossRef]

35. Toker, S.; Moseley, J.L. The Mental Model Comparison of Improvement Practitioners. Perform. Improv. Q. 2013, 29, 145-167.

36. Eisenberg, J.; Mattarelli, E. Building Bridges in Global Virtual Teams: The Role of Multicultural Brokers in Overcoming the Negative Effects of Identity Threats on Knowledge Sharing Across Subgroups. Int. Manag. 2017, 23, 399-411. [CrossRef]

37. Robert, L.P.; You, S. Are you satisfied yet? Shared leadership, individual trust, autonomy, and satisfaction in virtual teams. Assoc. Inf. Sci. Technol. 2018, 69, 503-513. [CrossRef]

38. Flavian, C.; Guinalíu, M.; Jordan, P. Antecedents and consequences of trust on a virtual team leader. Manag. Bus. Econ. 2018, 28, 2-24. [CrossRef]

39. Klitmøller, A.; Lauring, J. When global virtual teams share knowledge: Media richness, cultural difference and language commonality. World Bus. 2013, 48, 398-406. [CrossRef]

40. Villegas, A.Z.; Díaz, J.M. Experiential learning with global virtual teams: Developing intercultural and virtual competencies. Magis 2016, 9, 129-146. [CrossRef]

41. Cagiltay, K.; Bichelmeyer, B.; Akilli, G.K. Working with multicultural virtual teams: Critical factors for facilitation, satisfaction and success. Smart Learn. Environ. 2015, 2, 11. [CrossRef]

42. Wang, K. Social processes and team creativity in multicultural teams: A socio-technical framework. J. Organ. Behav. 2015, 45, 1080-1089. [CrossRef]

43. Han, S.J.; Beyerlein, M. Framing the Effects of Multinational Cultural Diversity on Virtual Team Processes. Small Group Res. 2016, 47, 351-383. [CrossRef]

44. Davidavičienè, V.; Raudeliūnienè, J. ICT in tacit knowledge preservation. In Proceedings of the 6th International Scientific Conference, Vilnius, Lithuania, 10-11 May 2010; pp. 822-828. [CrossRef]

45. Hortovanyi, L.; Ferincz, A. The impact of ICT on learning on-the-job. Learn. Organ. 2015, 22, 2-13. [CrossRef]

46. Lippert, H.; Dulewicz, V. A profile of high-performing global virtual teams. Team Perform. Manag. 2018, 24, 169-185. [CrossRef]

47. Pangil, F.; Chan, J.M. The mediating effect of knowledge sharing on the relationship between trust and virtual team effectiveness. Knowl. Manag. 2014, 18, 92-106. [CrossRef]

48. Hoch, J.E.; Dulebohn, J.H. Team personality composition, emergent leadership and shared leadership in virtual teams: A theoretical framework. Hum. Resour. Manag. Rev. 2017, 27, 678-693. [CrossRef]

49. Han, S.J.; Chae, C.; Macko, P.; Park, W.; Beyerlein, M. How virtual team leaders cope with creativity challenges. Eur. J. Train Dev. 2017, 41, 261-276. [CrossRef]

(C) 2020 by the authors. Licensee MDPI, Basel, Switzerland. This article is an open access article distributed under the terms and conditions of the Creative Commons Attribution (CC BY) license (http://creativecommons.org/licenses/by/4.0/). 